\title{
Estimation and examination of linepack pressures in long liquid pipelines
}

\author{
PRASHANTH REDDY HANMAIAHGARI ${ }^{1, *}$, RANGA REDDY KOTTAM ${ }^{2}$ and \\ MRINAL KAUSHIK ${ }^{3}$ \\ ${ }^{1}$ Department of Civil Engineering, Indian Institute of Technology Kharagpur, Kharagpur 721 302, India \\ ${ }^{2}$ Aker Solutions, Snarøyveien 36, 1364 Fornebu, Norway \\ ${ }^{3}$ Department of Aerospace Engineering, Indian Institute of Technology Kharagpur, Kharagpur 721 302, India \\ e-mail: hpr@civil.iitkgp.ac.in; ranga.kottam@akersolutions.com; mkaushik@aero.iitkgp.ac.in
}

MS received 19 November 2017; revised 31 December 2018; accepted 4 February 2019; published online 3 April 2019

\begin{abstract}
In the past, many researchers have carried out water-hammer pressure analysis using Joukowsky equation. However, it has been observed that the computed pressure surge is no longer applicable based on the equation. The Joukowsky equation cannot be used even within the reflection time of the long pipeline. In such cases, the actual pressure rise due to the sudden closure of a quick acting valve will be several times more than that of the sudden increase in pressure as calculated by the Joukowsky equation. The phenomenon of rising pressure at the upstream of an instantaneously closed valve with the passage of time caused by the pipe friction is commonly called as linepacking. In this paper, various parameters affecting the linepack pressure have been thoroughly investigated. As the relative roughness increases, the resulting non-dimensional linepack pressure $\left(P_{L P} / P_{o}\right)$ significantly increases and the proportionality constant was equal to 1.5 . The linepack pressure was determined to be decreasing with increasing valve closure time. The dominant parameter that influences the linepack pressure is found to be the Reynolds number as compared to the Mach number, and the relative roughness. Furthermore, the linepack pressure is found to be proportional to frictional head loss $\left(h_{L} / D\right)$, and inversely proportional to inlet pressure $\left(P_{o} /\left(\gamma L_{o}\right)\right)$. Finally, a linear regression equation was developed in terms of non-dimensional variables to estimate the linepack pressure using hand calculations without undergoing numerical modeling procedures. The proposed equation was validated for sudden valve closure pressure histories available in the literature. The proposed method is applicable to long distance water supply pipelines where the linepack pressures are significant.
\end{abstract}

Keywords. Pressure surge; water-hammer; linepack pressure; Joukowsky formula; instantaneous valve closure; numerical modeling.

\section{Introduction}

In addition to the sudden pressure rise caused by rapid valve closure, long liquid conveyance pipelines are also subjected to a delayed, slow pressure rise phenomenon, which is known as linepack. Rapid/sudden valve closure is defined as if the valve completely closes prior to the pressure wave initiated by the valve closure is reflected at the upstream boundary and reached back to the valve. In other words, when a valve is closed suddenly, linepack pressure at the valve gradually increases above the Joukowsky [1] pressure over the time perhaps due to skin friction effects. The linepack is defined as the increase in volume of the water/liquid present in the pipeline due to compressibility of water/liquid and elasticity of the pipeline

*For correspondence at any time. Importantly, linepacking represents the major energy loss gradient only in liquid pipelines and not applicable for gaseous flows.

In long water pipelines, pumps must produce higher delivery pressures to overcome the frictional losses. Whenever there is an occurrence of sudden valve closure, there will be a delay in the signal reaching the pump, during this delay, pump continuously delivering the water into the pipeline by packing the water. Due to the reversal of flow, the non-return valve on the downstream of the pump closes, and the water pressure between the two closed valves is even more than the design delivery pressure of the pump due to the pressure wave moving up and down between the valves. In addition, the linepack pressure, which is locked between the two valves is not released and induces pump startup problems. Although the linepack pressure is one of the complex problems in pipeline hydraulics, limited knowledge exists about the subject. Since the 1960s, there 
are a number of studies with various hypotheses that have been published to predict unsteady friction and resulting velocity distributions during sudden valve closures but not the linepack pressure. Therefore, the effect of valve closing particularly in long pipelines remains an unsolved problem in spite of its importance for safety and stability of pipe systems is widely recognized. About 45 years ago, Kaplan et al [2] understood linepack pressures from their field experience during unsteady oil flows and provided a comprehensive knowledge of the phenomenon. Initially, Kries [3] has given following equation to compute linepack at the quick closing valve.

$$
\frac{d P_{L P}}{d t} \approx \frac{1}{4} \frac{32 v}{D^{2}} \rho a V_{o}
$$

Where $P_{L P}$ is the linepack pressure, $t$ is the time duration in which linepack pressure starts building up and reaches the maximum linepack, $v$ is the kinematic viscosity, $D$ is the diameter of the conduit, $\rho$ is the mass density of water, $a$ is sonic velocity and $V_{o}$ is initial fluid velocity at the valve. However, Tijsseling and Anderson [4] reported that Kries [3] linepack formula Eq. (1) is unsatisfactory. The present study also found that the linepack formula given by Kries [3] is underestimating the actual linepack pressure to a great extent, i.e., the values obtained by this formula are $1 / 4^{\text {th }}$ to $1 / 10^{\text {th }}$ of the actual linepack pressures. Jung et al $[5,6]$ referred the pressure built up due to the increase in volume of water stored in the pipeline as linepacking which was greater than instantaneous water-hammer pressure rise after the initial flow comes to rest. Jung et al [5, 6] have concluded that design based on surge pressure given by the Joukowsky equation leads to a poor design. Jung et al [5, 6] concluded that the linepacking occurs because of the pressure accumulated in the pipe system due to the compressibility and elasticity of the fluid and pipe material.

\subsection{The Joukowsky equation}

The sudden closing of a valve will produce an instantaneous pressure rise upstream of the valve called the waterhammer pressure, is calculated by the Joukowsky equation

$$
\Delta P_{j}=\rho a \Delta V
$$

where the pressure increase $\Delta P_{j}$ is the positive surge caused by sudden valve closure, $\rho$ is the fluid mass density $(\mathrm{kg} /$ $\mathrm{m}^{3}$ ), $a$ is the wave propagation velocity through the fluid in the pipeline and $\Delta V$ is the instantaneous change in the homogeneous fluid velocity $(\mathrm{m} / \mathrm{s})$. The complete details of water-hammer are given by Watters [7], Fox [8], Thorley [9], and Wylie and Streeter [10] mainly for single-phase liquid pipelines but it is also applicable for two phase flows such as air bubbles in water. The Joukowsky equation (2) applies to only if (i) periods of time, which are either equal to or shorter than the reflection time of the pressure pulse
$T_{r}$; (ii) the period of time, which falls within the velocity change $\Delta V$ and, (iii) the pipes characterized by friction losses which falls within the limits of typical of liquid conveyance systems. If $\Delta V$ runs in the opposite direction to the flow the pressure will rise, else it will fall. If the liquid pumped is water, i.e., $\rho=1000 \mathrm{~kg} / \mathrm{m}^{3}$, Eq. (2) will be simplified as follows.

$$
h_{j}=\frac{a \Delta V}{g} \cong 140 \Delta V \text { for } a=1400 \mathrm{~m} / \mathrm{s}
$$

Where $g$ is the gravitational acceleration, $9.81 \mathrm{~m} / \mathrm{s}^{2}$ and $h_{j}$ in $\mathrm{m}$, is the change in pressure head caused due to the instantaneous change in velocity.

\subsection{Reflection time $\left(T_{r}\right)$}

A pressure wave is initiated at the valve due to its sudden closure. The wave propagates upstream and reflects back from the reservoir and travels up to the valve. The strength of the pressure wave diminishes as it propagates due to frictional losses. The cycle repeats till the wave completely dissipates because of the frictional losses in the pipe system. The time lag between the initiation of the pressure wave and its meeting again with the valve after reflection from the opposite end, is known as reflection time. The reflection time is denoted by $T_{r}$ which is equal to $2 L / a$.

It was assumed that the frictional head energy, which was earlier utilized by the flow, is released when the flow stops instantaneously in the pipeline, which in fact causes the gradual pressure rise. It is widely established that the Darcy-Weisbach equation (4) is the best method to calculate the energy loss caused by the skin friction in turbulent steady state pipe flow,

$$
h_{L}=\frac{\lambda L V_{o}^{2}}{2 g D}
$$

where, $\lambda(-)$ is the skin friction factor, $V_{o}(\mathrm{~m} / \mathrm{s})$ is the initial flow velocity, and $L(\mathrm{~m})$ is the conduit length, $D(\mathrm{~m})$ is the conduit diameter.

The objective of the present study is to develop a nondimensional equation for estimating linepack pressure caused by instantaneous closure of a valve in a simple (pipes in series without loops) water pipeline system. The non-dimensional equation requires only steady state frictional pressure loss in the pipe system and inlet pressure as inputs. The methodology is also valid for two-phase flows as in nuclear power plant cooling systems. As a first step in the methodology, dimensional analysis was carried out to identify important non-dimensional parameters affecting linepack pressure. The effects of various non-dimensional parameters on linepack pressure were studied and important non-dimensional parameters were identified. Followed by, validation of the proposed equation with experimental data 
available in the literature was presented. Finally, limitations of the model were discussed.

\section{Methodology}

In this study, continuity and momentum equations were used for solving unsteady flows in water pipelines. The linepack pressures in the pipe system, were computed using numerical modeling for the pipe configuration as given in figure 1. Steady-state skin friction factor was used in the numerical simulations. The methodology adopted in the numerical modeling of the pipe system is presented below.

\subsection{Pipe model}

Rapidly varying flow variables (water-hammer) in the conduit flows are functions of space $(x)$ and time $(t)$ coordinates. The spatial and temporal variations in pressure and velocity were calculated by solving the following continuity and momentum equations [11].

$$
\begin{gathered}
\frac{\partial H}{\partial t}+\frac{a^{2}}{g A} \frac{\partial Q}{\partial x}=0 \\
\frac{\partial Q}{\partial t}+g A \frac{\partial H}{\partial x}+\frac{\lambda Q|Q|}{2 D A}=0
\end{gathered}
$$

Here, $H=$ pressure head (pressure/density); $Q=$ flowrate $\left(\mathrm{m}^{3} / \mathrm{s}\right) ; a=$ pressure wave speed in the conduit; $A=$ conduit cross sectional area; $g=$ gravitational acceleration and $\lambda$ is friction factor. Equations (5) and (6) are simplified form of continuity and momentum equations by neglecting convective acceleration terms. The dynamic flow variables are obtained by solving Eqs. (5), and (6) with the appropriate initial and boundary conditions.

Graphical, numerical and algebraic methods are available to solve the hyperbolic partial differential Eqs. (5) and (6) and these methods are presented in detail by Wylie and Streeter [10]. The computational methods are generally based on numerical techniques, for example the method of characteristics (MOC), implicit finite difference methods and finite volume methods. The MOC belongs to the family of explicit numerical methods which require CFL (CourantFriedrichs-Lewy) condition to be satisfied [12]. In addition, the MOC requires small time steps to capture detailed unsteady flow variables. Small time step necessitates small grid size and together require a large number of computational time intervals and large number of grids to calculate unsteady flows in large networks. Therefore, application of the MOC for field water pipe networks requires a computer program. To date, many computer programs were developed by government and commercial companies based on the MOC which include the algorithms for handling pipe junctions, pumps, valve, surge tanks, and cavitation. The implementation details of the method of characteristics pertinent to the various equipment within the water distribution system are given in numerous publications [7, 10, 13, 14]. Henceforth, in the present study, the method of characteristics has been implemented for its accuracy and robustness.

\subsection{Valve modelling}

Valve is an important component of the pipe systems, which is used to control the flow of water by opening, closing or partially constricting the flow across it. In principle, a valve regulates the flow by offering a variable pressure drop of the fluid flowing across it. The pressure drop across the valve depends on factors such as valve characteristics, area of opening and flow rate through the valve. Valve modeling procedure as presented by Chaudhry [13] and Hanmaiahgari et al [10] was followed in this paper. For brevity, only an outline of the methodology adopted in this work is presented here.

$$
Q_{o}=\left(C_{v}\right)_{o} \sqrt{\Delta P_{o}}
$$

In Eq. (7), $\left(C_{v}\right)_{o}$ represents the flow coefficient; $Q_{o}$ is the flowrate, and $\Delta P_{o}$ is the pressure loss across the valve, the

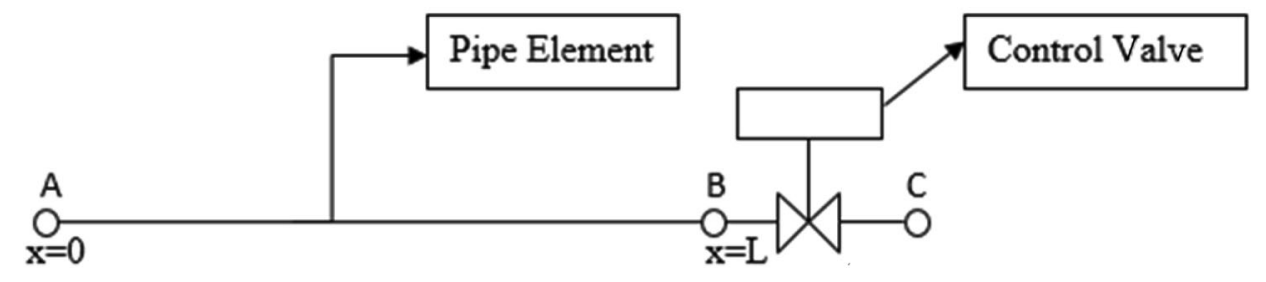

$A=$ Inlet node

$B=$ Junction between pipe and valve

$\mathrm{C}=$ Outlet of valve

Figure 1. Schematic of pipe system used in numerical simulations. 
subscript 'o' refers to the steady-state flow conditions. The Eq. (7) may be written for the changed flow during unsteady-state flow conditions as follows,

$$
Q_{P}=\left(C_{v}\right)_{P} \sqrt{\Delta P_{P}}
$$

where $\left(C_{v}\right)_{P}$, is the flow coefficient during unsteady-state flow condition; $Q_{P}$, is the flowrate at next time level during unsteady-state flow conditions and $\Delta P_{P}$, is the pressure loss across the valve during unsteady-state flow conditions. Eq. (8) is divided by Eq. (7) and squaring on either side gives following equation,

$$
Q_{P}^{2}=\left(Q_{o} s\right)^{2} \frac{\Delta P_{P}}{\Delta P_{o}}
$$

where,

$$
s=\frac{\left(C_{v}\right)_{P}}{\left(C_{v}\right)_{o}}
$$

Eq. (9) is solved simultaneously with positive MOC characteristic equation [13] to compute $Q_{P}$ and $\Delta P_{P}$. Note that $s=1.0$ corresponds to the full opening at which the flow through the valve is $Q_{o}$ under a head of $\Delta P_{o}$. Value of $s$ is decreased linearly from 1.0 to 0 during the valve closure time.

\subsection{Friction modelling}

In this study, friction factor $\lambda$ was determined using Haaland explicit approximation of the Moody diagram [15] as given below.

$$
\frac{1}{\sqrt{\lambda}}=-1.8 \log _{10}\left[\left(\frac{\varepsilon / D}{3.7}\right)^{1.11}+\frac{6.9}{R_{e}}\right]
$$

Where $\lambda=$ Darcy friction factor $(-) ; \varepsilon / D=$ Relative Roughness; $R_{e}=$ Reynolds number $=\frac{4 Q}{\pi v D} ; v=$ kinematic viscosity $\left(\mathrm{m}^{2} / \mathrm{s}\right)$ of water; $Q=$ volumetric flowrate of water $\left(\mathrm{m}^{3} / \mathrm{s}\right)$.

\subsection{Dimensional analysis}

Linepack pressure is a complex and very common unsteady pressure phenomenon. An accurate estimation of linepack pressure using analytical method is not yet available. In this paper, recourse was taken to study the phenomenon using a regression equation in terms of non-dimensional variables. In closed conduit flows, flow depends on the forces of inertia, viscous, flow velocity and sound velocity properties of the flow and the boundary conditions. Dimensional analysis was used as a tool to study the significant groupings of these parameters. Among the dimensional groupings which are of importance to the present research problem were Reynolds number and Mach number. These groups should be of the same value both in the model and in the prototype for complete similitude. The following analysis was limited to the estimation of linepack pressure in a pipe system which has the upstream reservoir/pump with a constant pressure and a rapid closure of the terminal valve. In this analysis, the following eight parameters influencing the linepack pressure were considered.

$$
P_{L P}=f\left(a, P_{o}, V_{o}, D, v, \varepsilon, L, h_{L}\right)
$$

The dimensionless groups of dimensional characteristic parameters were determined using the Buckingham Pi theorem as mentioned below.

$$
\frac{P_{L P}}{P_{o}}=f_{1}\left(\frac{V_{o}}{a}, \frac{V_{o} D}{v}, \frac{\varepsilon}{D}, \frac{h_{L}}{D}, \frac{P_{f L}}{P_{o}}, \frac{P_{o}}{\gamma L_{o}}\right)
$$

$$
\frac{P_{L P}}{0.5 \rho V_{o}^{2}}=f_{2}\left(\frac{V_{o}}{a}, \frac{V_{o} D}{v}, \frac{\varepsilon}{D}, \frac{h_{L}}{D}, \frac{P_{f L}}{0.5 \rho V_{o}^{2}}, \frac{P_{o}}{\gamma L_{o}}\right)
$$

Where $P_{f L}=$ steady-state head loss (bar), $P_{o}=$ inlet pressure (bar); $a=$ wave velocity $(\mathrm{m} / \mathrm{s}) ; P_{L P}=$ pressure rise due to linepack (bar); $\frac{V_{o}}{a}=$ Mach number; $\frac{V_{o} D}{v}=$ Reynolds number; $\varepsilon=$ pipe roughness height $(\mathrm{m}) ; D=$ pipe diameter (m); $L=$ pipe length $(\mathrm{m}) ; h_{L}=$ steady-state head loss $(\mathrm{m})$; $V_{o}=$ steady-state velocity $(\mathrm{m} / \mathrm{s})$; and $v=$ kinematic viscosity $\left(\mathrm{m}^{2} / \mathrm{s}\right)$.

The influence of $\frac{P_{f L}}{P_{o}}$ on $\frac{P_{L P}}{P_{o}}$ was clearly observed in Eq. (12a). Similarly influence of $\frac{P_{f L}}{0.5 \rho V_{o}^{2}}$ on $\frac{P_{L P}}{0.5 \rho V_{o}^{2}}$ was also observed in Eq. (12b). Finally, a linear equation was developed in which $\frac{P_{L P}}{P_{o}}$ was expressed in terms of $\frac{P_{f L}}{P_{o}}$ because easy availability of inlet pressure value and steady state frictional head-loss as compared to the density and inlet velocity. Further, the developed equation (12a) independent of density is applicable to both incompressible and compressible flows. The developed non-dimensional equation was presented in detail in the results and discussion section.

\subsection{Numerical simulations}

The proposed methodology was developed from the data generated by numerical simulations of a simple pipeline as given in figure 1 . The hypothetical pipeline consisted of a reservoir/pump with a constant inlet pressure at the upstream end and a terminal valve at the downstream end. These numerical simulations were carried out for varied pipeline characteristics and boundary conditions to obtain the corresponding linepack pressures. Here, the boundary conditions were specified as inlet pressure, flow rate and instantaneous closure of the downstream valve.

In the simulations, the pipe material considered was ANSI B36.10 with schedule 40, which has wave speeds of $1409 \mathrm{~m} / \mathrm{s}$ and $1260 \mathrm{~m} / \mathrm{s}$ without and with expansion joints, respectively. The roughness heights were considered as 
Table 1. Details of numerical simulations carried out to study linepack pressures.

\begin{tabular}{|c|c|c|c|c|c|c|c|c|c|c|}
\hline$P_{o}(\mathrm{bar})$ & $\varepsilon(\mathrm{m})$ & $a(\mathrm{~m} / \mathrm{s})$ & $D(\mathrm{~m})$ & $L(\mathrm{~m})$ & $V_{o}(\mathrm{~m} / \mathrm{s})$ & $R_{\mathrm{e}}$ & $C_{v} \mathrm{~m}^{3} / \mathrm{h} / \sqrt{b a r}$ & $H_{s}(\mathrm{bar})$ & $h_{L}($ bar $)$ & $P_{L P}($ bar $)$ \\
\hline \multicolumn{11}{|c|}{ Pipe material 1} \\
\hline 10.00 & $4.57 \times 10^{-5}$ & 1405 & 0.0635 & 10000 & 0.677 & 42990 & 10 & 1.57 & 8.43 & 7.27 \\
\hline 15.60 & $4.57 \times 10^{-5}$ & 1409 & 0.0381 & 10000 & 0.679 & 25870 & 10 & 1.10 & 14.50 & 11.89 \\
\hline 5.82 & $4.57 \times 10^{-5}$ & 1405 & 0.0635 & 5000 & 0.680 & 43180 & 10 & 1.57 & 4.25 & 3.52 \\
\hline 8.35 & $4.57 \times 10^{-5}$ & 1409 & 0.0381 & 5000 & 0.680 & 25889 & 10 & 1.10 & 7.25 & 6.09 \\
\hline 5.00 & $4.57 \times 10^{-5}$ & 1405 & 0.0635 & 10000 & 0.435 & 27623 & 10 & 1.23 & 3.77 & 3.34 \\
\hline 7.50 & $4.57 \times 10^{-5}$ & 1409 & 0.0381 & 10000 & 0.436 & 16593 & 10 & 1.04 & 6.46 & 5.59 \\
\hline 3.13 & $4.57 \times 10^{-5}$ & 1405 & 0.0635 & 5000 & 0.436 & 27686 & 10 & 1.24 & 1.89 & 1.58 \\
\hline 4.28 & $4.57 \times 10^{-5}$ & 1409 & 0.0381 & 5000 & 0.436 & 16612 & 10 & 1.04 & 3.24 & 2.76 \\
\hline \multicolumn{11}{|c|}{ Pipe material 2} \\
\hline 9.65 & $2.54 \times 10^{-5}$ & 1260 & 0.0635 & 10000 & 0.680 & 43180 & 10 & 1.60 & 8.05 & 6.92 \\
\hline 16.26 & $2.54 \times 10^{-5}$ & 1260 & 0.0381 & 10000 & 0.680 & 25908 & 10 & 1.08 & 15.18 & 12.08 \\
\hline 5.62 & $2.54 \times 10^{-5}$ & 1260 & 0.0635 & 5000 & 0.680 & 43180 & 10 & 1.60 & 4.02 & 3.40 \\
\hline 8.67 & $2.54 \times 10^{-5}$ & 1260 & 0.0381 & 5000 & 0.680 & 25908 & 10 & 1.08 & 7.59 & 6.40 \\
\hline 4.85 & $2.54 \times 10^{-5}$ & 1260 & 0.0635 & 10000 & 0.436 & 27661 & 10 & 1.25 & 3.60 & 3.21 \\
\hline 7.87 & $2.54 \times 10^{-5}$ & 1260 & 0.0381 & 10000 & 0.436 & 16593 & 10 & 1.03 & 6.84 & 5.80 \\
\hline 3.05 & $2.54 \times 10^{-5}$ & 1260 & 0.0635 & 5000 & 0.436 & 27671 & 10 & 1.25 & 1.80 & 1.54 \\
\hline 4.45 & $2.54 \times 10^{-5}$ & 1260 & 0.0381 & 5000 & 0.436 & 16594 & 10 & 1.03 & 3.42 & 2.97 \\
\hline
\end{tabular}

$4.57 \times 10^{-5} \mathrm{~m}$ and $2.54 \times 10^{-5} \mathrm{~m}$, henceforth, these pipe materials were referred as pipe material 1 and pipe material 2. Two different flow velocities, with two different pipe lengths, with two different pipe diameters and with two different roughness heights (two pipe materials) were considered in combinations. Therefore, a total of 16 simulations were carried out in the study. Details of both the pipe materials used in the numerical simulations were given in table 1 .

\section{Results and discussion}

\subsection{Effect of various non-dimensional parameters on linepack pressure}

The linepack pressures are negligibly small for shorter pipes, however, they must be taken into account for long pipe systems. As per the existing hydraulic literature, the linepack pressure in the long pipes becomes considerable and it is comparable to the water-hammer pressures. The linepack pressures are found to be even more than the water-hammer pressures for water transmission lines more than $15 \mathrm{~km}$ long. In major cities across the world the water conveyance systems easily stretch more than $15 \mathrm{~km}$ from the source point to supply distribution network. Thus, the linepack pressure becomes an important parameter in the analysis of commercial pipe systems. In the open literature, numerous researchers worked on modeling of unsteady flows in pipe systems, however, the estimation of linepack is hardly looked into. It had been reported that the value of linepack pressure is almost directly proportional to the steady-state frictional loss [16, 17]. But there was no quantification of the linepack pressure and no study was found in the literature which provides an accurate relationship between the linepack pressure and the steady-state head loss. As of now, the only available method to compute the linepack pressure is the complex one-dimensional numerical modeling of an unsteady flow in a pipeline. Therefore, an attempt was made in the present investigation to estimate the linepack pressure in a series pipe system using a simple regression equation, which can be readily used by the field engineers.

Simulated pressure histories due to the sudden closure of terminal valve (closed in one second linearly) for different pipe roughness were plotted in figure 2. In this figure, linepack pressure and an instantaneous pressure rise given by the Joukowsky equation were demonstrated for better understanding. In addition, the variation of non-dimensional linepack pressure as a function of non-dimensional closing time of a sudden valve closure can be seen in the

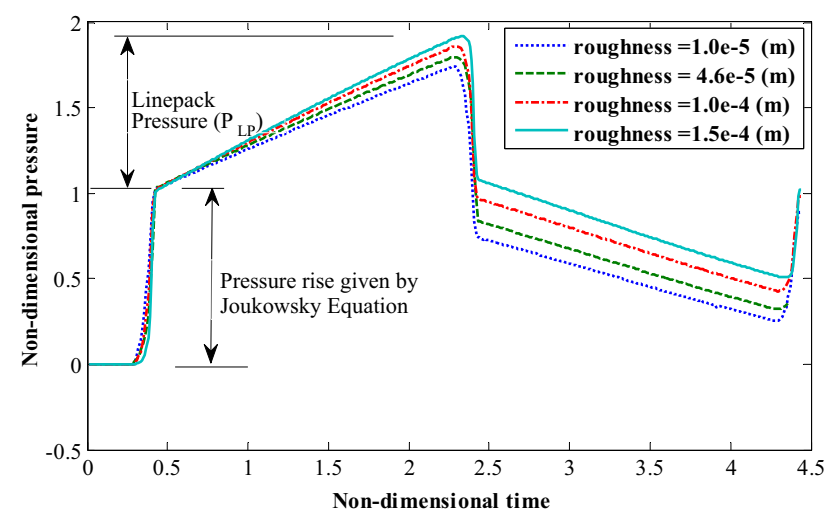

Figure 2. Change in linepack pressure due to change in roughness height. 
Table 2. The Variation of linepack pressure with variation in pipe wall roughness.

\begin{tabular}{|c|c|c|c|c|c|c|}
\hline $\begin{array}{l}\text { Diameter } \\
(\mathrm{m})\end{array}$ & $\begin{array}{l}\text { Roughness } \\
\text { height }(\mathrm{m})\end{array}$ & $\begin{array}{c}\text { Relative } \\
\text { Roughness }(\varepsilon / \\
\text { D) }\end{array}$ & $\begin{array}{c}\text { Maximum non- } \\
\text { dimensional linepack } \\
\text { pressure }\end{array}$ & $\begin{array}{c}\text { Increase in } \\
\text { linepack pressure } \\
\text { (bar) }\end{array}$ & $\begin{array}{l}\text { Percentage change in } \\
\text { linepack pressure }(\%)\end{array}$ & $\begin{array}{l}\text { Pipe System } \\
\text { Properties }\end{array}$ \\
\hline 0.0635 & $1.00 \times 10^{-5}$ & $1.57 \times 10^{-4}$ & 0.74 & - & & $a=1404.5 \mathrm{~m} / \mathrm{s}$ \\
\hline 0.0635 & $4.60 \times 10^{-5}$ & $7.24 \times 10^{-4}$ & 0.81 & 0.07 & 9.5 & $L_{o}=10000 \mathrm{~m}$ \\
\hline 0.0635 & $1.00 \times 10^{-4}$ & $1.57 \times 10^{-3}$ & 0.86 & 0.05 & 6.2 & $Q_{o}=0.0021 \mathrm{~m}^{3} /$ \\
\hline 0.0635 & $1.50 \times 10^{-4}$ & $2.36 \times 10^{-3}$ & 0.92 & 0.06 & 7.0 & $\begin{array}{c}\mathrm{s} \\
P_{o}=10 \mathrm{bar} \\
C_{v}=10 \mathrm{~m}^{3} / \mathrm{h} / \\
\sqrt{b a r}, \\
\text { Valve closure } \\
\text { time }=1 \mathrm{~s}\end{array}$ \\
\hline
\end{tabular}

figure 2. The details of the pipe system used in the study were given in table 2 . The non-dimensionlized pressure was obtained as $\left(H-H_{s}\right) g /\left(a V_{o}\right)$, where $H$ is the dynamic pressure head at the valve, $H_{s}$ is steady-state pressure head at the valve, $a$ is the wave velocity and $V_{o}$ is steady-state velocity in the pipe system. The non-dimensionlized time was given as $a t / L$, where $L$ is the pipe length in meters and $t$ is the time in seconds. The standard roughness height of the pipe material ANSIB36.10 with schedule 40 is $4.6 \times 10^{-5} \mathrm{~m}$. To study the effect of roughness on the linepack pressure, the roughness height was varied from $1.0 \times 10^{-5} \mathrm{~m}$ to $1.5 \times 10^{-4} \mathrm{~m}$. Figure 2 has clearly demonstrated the rise in linepack pressure with increase in the roughness.

The variation of linepack pressure due to the increase in relative roughness was given in table 2 which has shown that the linepack pressure increases with the increasing wall roughness. By increasing the wall roughness to $14 \%$, the resulting increase in linepack pressure was $22.7 \%$. The increment in linepack pressure was considerable as evident from the percentage increase of linepack pressure produced by the increased roughness height. It is important to note that the percentage increase in linepack pressure was proportional to increase in wall surface roughness and the value of the proportionality constant is found to be 1.5 .

The effect of closing duration of a terminal valve on the linepack pressure was illustrated in figure 3 . The valve closing time was varied from 1 to $2.5 \mathrm{~s}$ in steps of $0.5 \mathrm{~s}$. In all simulations, the valve was closed linearly and coefficient of the valve was kept constant. It can be seen that the instantaneous pressure rise was shifting from left to right with the increase of valve closing time as shown in figure 3. However, the magnitude of instantaneous pressure rise was the same, i.e., the water-hammer pressure rise was not a function of the time taken by a terminal valve to close when the valve was completely closed before the reflected pressure wave arrived from upstream or downstream. Gudmundsson et al [16] reported that most of the water-hammer pressure produced while the valve closed from 80 to $100 \%$ and pressure increase was not that significant during the valve closure from 0 to $80 \%$. This observation was practically significant that a valve that closed in $t$ seconds, generated most of the water-hammer pressure head in the final $0.2 t$ seconds. The most important feature observed in figure 3, was the decrease in linepack pressure with the increased valve closure time, which was shown in the inset box. However, the decrement of linepack pressure was very small but finite. The variation of linepack pressure with varying valve closing time was also given in table 3 . The percentage change in linepack pressure was quite significant up to $6.3 \%$ when the valve closure time was varied from 1 to $2.5 \mathrm{~s}$. However, the percentage change in linepack pressure was almost insignificant for all valve closure times more than $2.5 \mathrm{~s}$. Therefore, it may be concluded that the valve must be closed slowly to control the linepack pressure.

The variation of the linepack pressure was plotted against varying steady-state velocity as shown in figure 4 . The linepack pressure $\left(P_{L P}\right)$ was made non-dimensional with inlet pressure $\left(P_{o}\right)$ and steady-state velocity $\left(V_{o}\right)$ was nondimensionalized with wave speed $(a)$. The analysis was

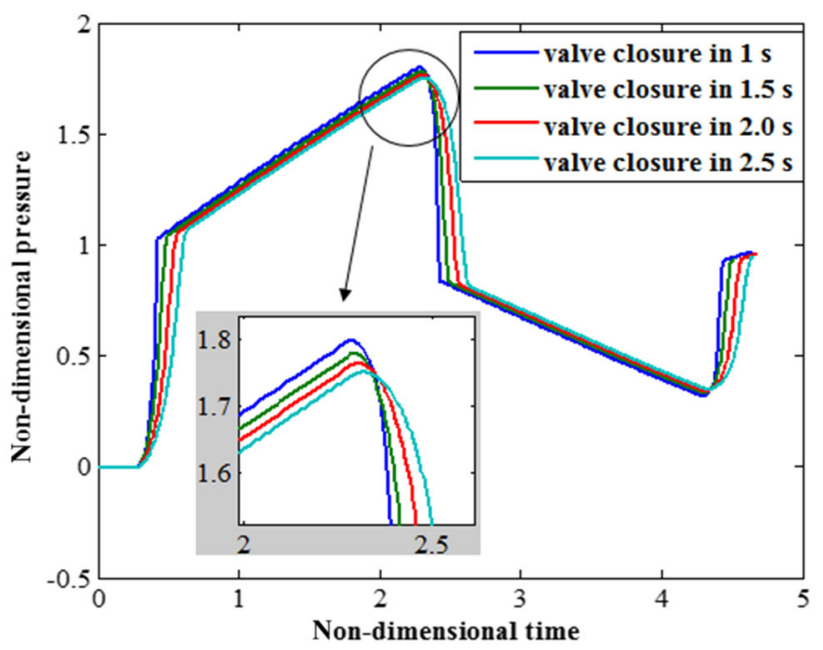

Figure 3. Change in linepack pressure due to change in valve closing time. 
Table 3. Variation of linepack pressure due to increase in valve closing time.

\begin{tabular}{lccc}
\hline $\begin{array}{l}\text { Valve } \\
\text { closure } \\
\text { time (s) }\end{array}$ & $\begin{array}{c}\text { Maximum non- } \\
\text { dimensional } \\
\text { linepack } \\
\text { pressure }\end{array}$ & $\begin{array}{c}\text { Percentage } \\
\text { decrease in } \\
\text { linepack } \\
\text { pressure (\%) }\end{array}$ & $\begin{array}{c}\text { Pipe system } \\
\text { properties }\end{array}$ \\
\hline 1.0 & 0.80 & & $a=1404.5 \mathrm{~m} / \mathrm{s}$ \\
1.5 & 0.78 & 2.5 & $L_{o}=10000 \mathrm{~m}$ \\
2.0 & 0.76 & 2.5 & $D=0.0635 \mathrm{~m}$ \\
2.5 & 0.75 & 1.3 & $\begin{array}{c}Q_{o}=0.0021 \mathrm{~m}^{3} / \mathrm{s} \\
P_{o}=10 \mathrm{bar} \\
\end{array}$ \\
& & & $C_{v}=10 \mathrm{~m}^{3} / \mathrm{h} /$ \\
& & $\sqrt{\mathrm{bar}^{-5}}$ \\
& & & $4.6 \times 10^{-5} \mathrm{~m}$ \\
\hline
\end{tabular}

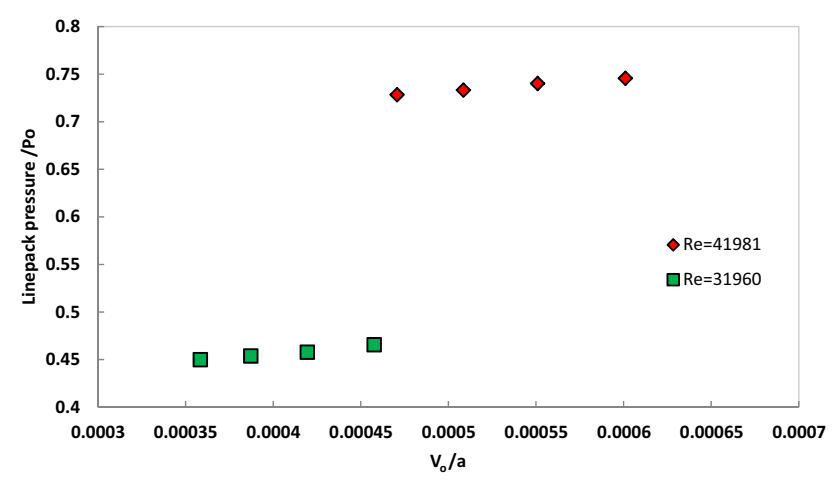

Figure 4. Variation of linepack pressure due to change in steadystate velocity.

performed for two Reynolds numbers, $R_{\mathrm{e}}=31960$, and $R_{\mathrm{e}}=41981$. In this plotting (figure 4) relative roughness was kept constant. Though, the linepack pressure $\left(P_{L P} / P_{o}\right)$ increases with increasing velocity, $\left(V_{o} / a\right)$ as shown in figure 4, however, the rate of increase was very small. Further, it may be interpreted that for the given Reynolds number, the steady-state velocity $\left(V_{o}\right)$ was kept constant and wave velocity $(a)$ was varied. The analysis concludes that a slight increase in the Reynolds number for a constant Mach number considerably increases linepack pressure, however, increase in the linepack pressure is negligible with the increasing Mach number for a given Reynolds number.

The variation of non-dimensional linepack pressure $\left(P_{L P} / P_{o}\right)$ with varying relative roughness $(\varepsilon / D)$ was plotted in figure 5. The analysis was performed for two Reynolds numbers, $R_{\mathrm{e}}=31960$ and $R_{\mathrm{e}}=41981$ and for a given Reynolds number, the steady-state velocity $\left(V_{o}\right)$ was kept constant, but the roughness height $(\varepsilon)$, was varied. The resulting linepack pressure $\left(P_{L P} / P_{o}\right)$ was increased considerably with increasing relative roughness, $(\varepsilon / D)$ for a given Reynolds number as shown in figure 5. In addition, increase in linepack pressure was substantial with increasing Reynolds number while keeping the relative roughness

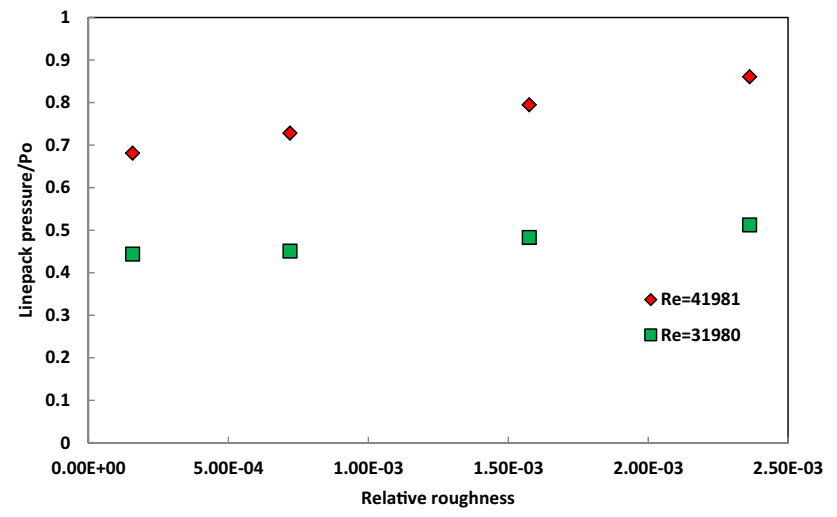

Figure 5. Variation of linepack pressure caused by variation in relative roughness $(\varepsilon / D)$.

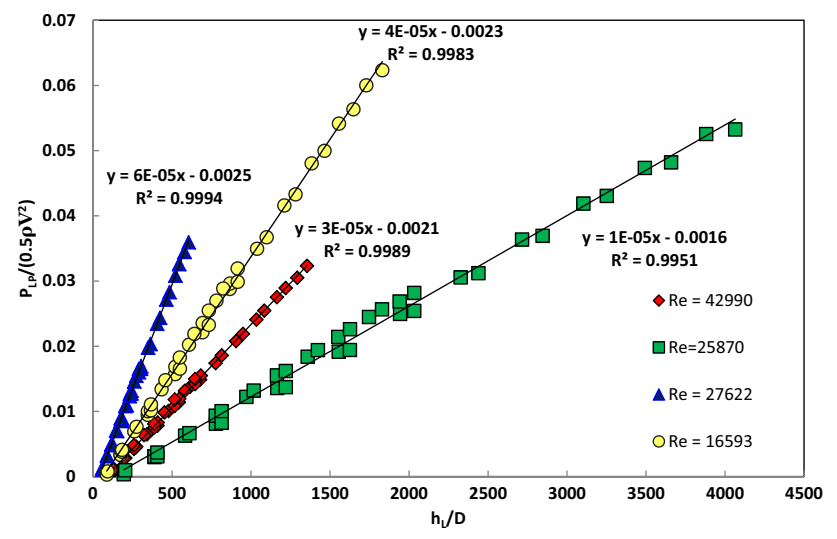

Figure 6. Variation of non-dimensional linepack pressure with varying non-dimensional steady-state friction loss.

as a constant. The conclusions obtained from the analysis of figures 5 and 6 were consistent with respect to the Reynolds number. The reason behind such a behavior is attributed to the friction factor which was a function of both the Reynolds number $\left(R_{e}\right)$ and the relative roughness $(\varepsilon / D)$. However, the more dominant parameter affecting the linepack pressure was found to be the Reynolds number.

The variation of non-dimensional linepack pressure $\left(P_{L P} /\left(0.5 \rho V_{o}^{2}\right)\right)$ with respect to change in non-dimensional steady-state head loss $\left(h_{L} / D\right)$ was plotted in figure 6 for four different Reynolds numbers $R_{\mathrm{e}}=16593,25870,27622$ and 42990. In these simulations, the relative roughness and the Mach number were varied while the Reynolds number was kept constant and the corresponding linepack pressures were computed. A linear relation exists between non-dimensional linepack pressure $\left(P_{L P} /\left(0.5 \rho V_{o}^{2}\right)\right)$ and non-dimensional steady-state headloss $\left(h_{L} / D\right)$ as observed in figure 6 . The intercept of lines on $h_{L} / D$ axis was found to be the same and however, the slope was changing with the varying Reynolds number. Analysis of the data plotted in figure 6 revealed that the slope of the linear relationship was a function of $P_{o} /\left(\gamma L_{o}\right)$, where $P_{o}$ is inlet pressure, $\gamma$ is 
the self-weight of the water, $L_{o}$ is pipe length between source node and valve location. In this analysis, for $R_{\mathrm{e}-}$ $=42990,25870,27622$ and 16610, the corresponding $P_{o} /\left(\gamma L_{o}\right)$ were $1.09 \times 10^{-7}, 1.68 \times 10^{-7}, 5.66 \times 10^{-8}$ and $8.35 \times 10^{-8}$, respectively. Similarly for $R_{\mathrm{e}}=42990$, 25870,27622 and 16610 the corresponding slopes of regression lines were $3.0 \times 10^{-5}, 10 \times 10^{-5}, 6.0 \times 10^{-5}$, and $4.0 \times 10^{-5}$, respectively. The slopes of linear regression lines were in the order of $6.0 \times 10^{-5}>$ $4.0 \times 10^{-5}>3.0 \times 10^{-5}>1.0 \times 10^{-5}$ and their corresponding values of $P_{o} /\left(\gamma L_{o}\right)$ were in decreasing order as $5.66 \times 10^{-8}<8.35 \times 10^{-8}<1.09 \times 10^{-7}<1.68 \times$ $10^{-7}$. Therefore, it was observed from the above analysis that the slope of the regression line is inversely proportional to $P_{o} /\left(\gamma L_{o}\right)$. It was also concluded from figure 6 that $P_{L P} / \frac{1}{2} \rho V_{o}^{2}$ linearly increases with increase in $h_{L} / D$ and inversely proportional to $P_{o} /\left(\gamma L_{o}\right)$.

\subsection{Non-dimensional equation}

It was established that numerical simulation results are always in good agreement with experimental unsteady pressure waveform in the positive half-cycle [18]. Therefore, the numerical results are considered as good as experimental measurements as far as first peak is concerned. The variation of non-dimensional linepack pressure $\left(P_{L P} / P_{o}\right)$ with nondimensional steady state frictional pressure loss $\left(P_{f L} / P_{o}\right)$ for

(a)

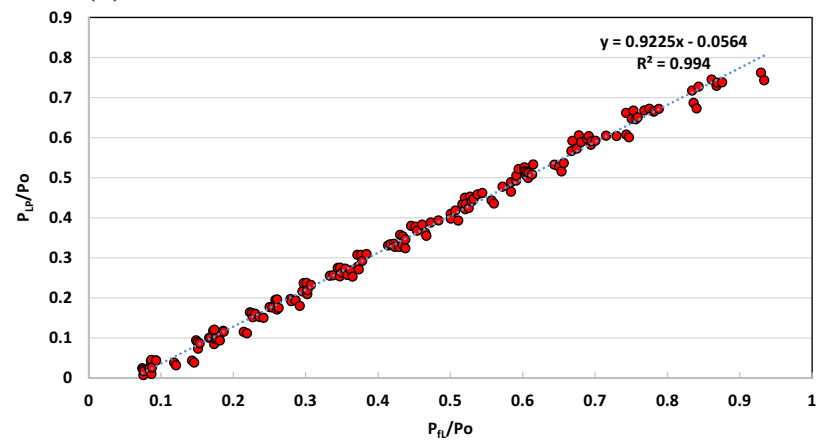

(b)

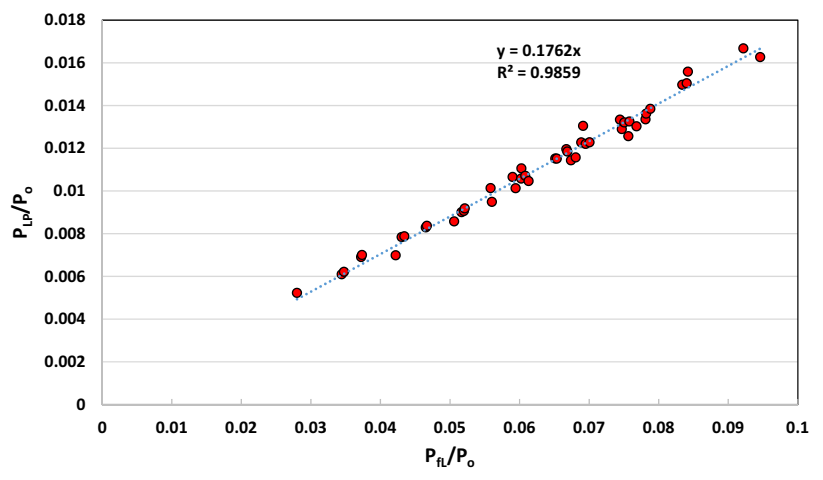

Figure 7. Plot between linepack pressure and steady-state head loss for (a) $\left(P_{f L} / P_{o}>0.1\right)$. b $\left(P_{f L} / P_{o}<0.1\right)$. both pipe materials 1 and 2 was shown in figure 7 . The datasets used for plotting figures $7 \mathrm{a}$ and $\mathrm{b}$ were analyzed with the Statistical Package for the Social Science (SPSS). Linear regression equation and power law were equally good among other regression relations based on the ANOVA test statistic. However, linear relation was chosen between dependent and independent variables due to its simplicity and ease of use. Hence the linepack pressure was expressed as a near function of steady-state head loss in the following equations,

$P_{L P / P_{o}}=\left\{\begin{array}{l}k_{11}\left(P_{f L} / P_{o}\right)+k_{12} ; \text { for } P_{f L} / P_{o}>0.1 \\ k_{13}\left(P_{f L} / P_{o}\right) ; \text { for } P_{f L} / P_{o}<0.1\end{array}\right.$

where, $P_{L P}$ is linepack pressure (bar), $P_{f L}$ is frictional loss (bar) and $P_{o}$ is inlet pressure (bar). If the ratio of frictional loss $\left(P_{f L}\right)$ to inlet pressure $\left(P_{o}\right)$ is greater than 0.1 , Eq. (13a) was used. In Eq. (13a), coefficients (with $95 \%$ confidence bounds): $k_{11}=0.92 \quad(0.91,0.93)$ and $k_{12}=-0.056(-0.062,-0.05)$. The aforesaid regression equation was obtained using numerical simulations with two pipe materials. If only pipe material 1 was used, then the regression constants were $k_{11}=0.93$ and $k_{12}=-0.06$. Similarly, for pipe material 2 , the regression constants were $k_{11}=0.92$ and $k_{12}=-0.052$. In all the cases, the coefficient of correlation was found to be above 0.993. The percentage change in constant $k_{11}$ was less than $1 \%$ and in constant $k_{12}$ was about $8 \%$, due to the change in pipe material. Thus, it can be said that the regression constants were insensitive to the pipe material. The uncertainties in $k_{11}$ and $k_{12}$ were computed as 0.01 and 0.006 , respectively. If the ratio of frictional loss $\left(P_{f L}\right)$ to inlet pressure $\left(P_{o}\right)$ is less than 0.1, Eq. (13b) was used. In Eq. (13b), coefficient (with $95 \%$ confidence bounds): $k_{13}=0 . .18(0.17,0.18)$ and the value of $k_{13}$ was obtained using numerical simulations with two pipe materials. The uncertainty in estimating $k_{13}$ was 0.0068 . In this case, the coefficient of correlation was found to be above 0.986. The Eq. (13b) was applicable for estimating linepack pressures near the inlet, whereas Eq. (13a) was applicable for estimating linepack pressures far away from the inlet boundary. Therefore, Eq. (13a, b) may be used to compute linepack pressures anywhere along the pipeline between inlet and valve.

The total pressure rise $\left(P_{\text {surge }}\right)$ including instantaneous pressure rise and slow pressure rise caused by the sudden valve closure may be computed by using Eq. (14),

$$
P_{\text {surge }}=\frac{\rho a V_{o}}{10^{5}}+P_{L P}
$$

where $P_{\text {surge }}$ is total positive pressure surge (bar), $\rho$ is mass density of water $\left(\mathrm{kg} / \mathrm{m}^{3}\right), a$ is wave velocity $(\mathrm{m} / \mathrm{s}), V_{o}$ is steady state velocity at the inlet of the regulating valve and $P_{L P}$ is linepack pressure (bar) computed using Eq. (13). A simple flow chart explaining the application of the proposed model is presented in figure 8 for its easy implementation. 


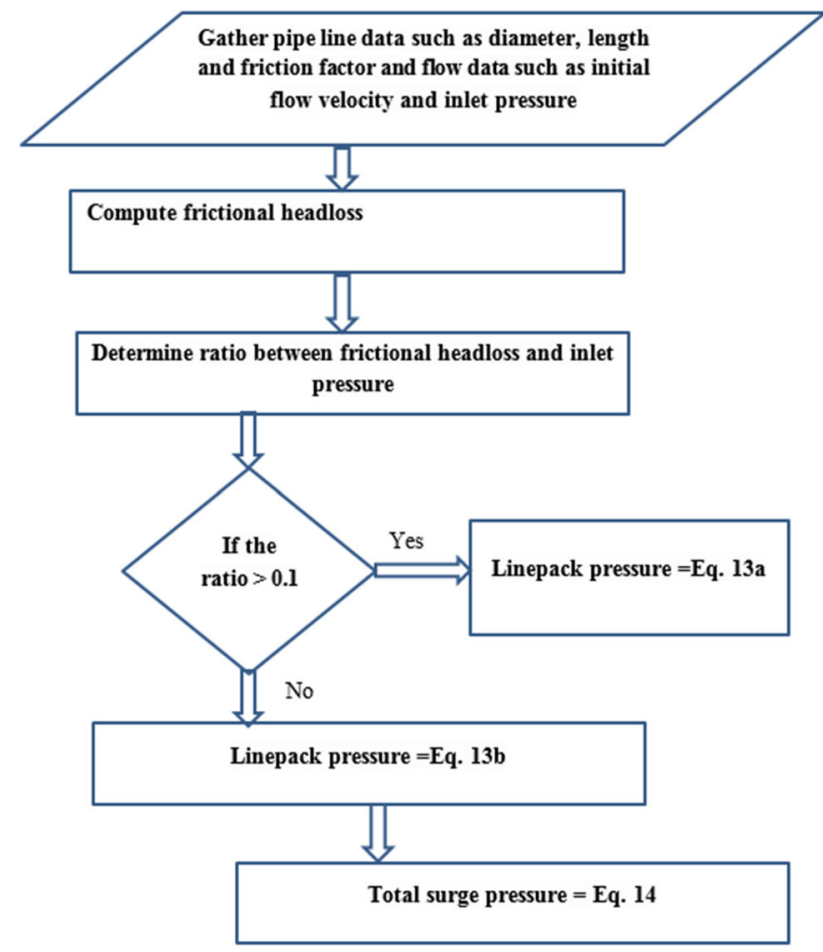

Figure 8. Flow chart of the proposed model.

\subsection{Validation of non-dimensional equation}

The proposed linear regression equation (Eq. 13) to estimate linepack pressure was validated with sudden valve closure pressure histories available in the literature. The validation results were presented in tables $4,5,6$. The measured and estimated linepack pressures using the Eq. (13), percentages of errors in the estimation and description of the experimental setups were given in tables $4,5,6$. The non-dimensional steady-state friction loss was small for small lengths, i.e., $P_{f L} / P_{o}<0.1$. Therefore, in most of the cases Eq. 13(b) was used because of small pipe lengths.

For the experimental set-up used by Adamkowski and Lewandowski [19] with the following parameters, pipe length
$\left(L_{o}\right)=98.11 \mathrm{~m}$, inlet pressure $\left(P_{o}\right)=127.5 \mathrm{~m}$, pipe diameter $(D)=0.016 \mathrm{~m}$, and wave velocity $(a)=1298.4 \mathrm{~m} / \mathrm{s}$. Measured and computed linepack pressures for this case were given in table 4.

Ellis [20] presented sudden valve closure experiments of Um Ghafa Water Project with the following parameters. It is a simple pipe system consisting of a reservoir at the upstream end and a gate valve at the downstream end. Pipe material is DI; Pipe length $\left(L_{o}\right)=19757 \mathrm{~m}$; inlet pressure $\left(P_{o}\right)=72.75 \mathrm{~m}$; pipe diameter $(D)=0.45 \mathrm{~m}$; and wave velocity $(a)=1113 \mathrm{~m} / \mathrm{s}$. Measured and computed linepack pressures were given in Table $6 \mathrm{~b}$.

Measured and computed linepack pressures were given in table 6 for the experiments carried out by Kucienska et al [21] and Kucienska [22] with the following parameters. Pipe length $\left(L_{o}\right)=50 \mathrm{~m}$; inlet pressure $\left(P_{o}\right)=60 \mathrm{~m}$; pipe diameter $(D)=0.02 \mathrm{~m}$; wave velocity $(a)=280 \mathrm{~m} / \mathrm{s}$ and steady state velocity $\left(V_{o}\right)=5 \mathrm{~m} / \mathrm{s}$.

In all the experimental cases used for validation, the percentage of error in the estimated values was between 0.53 and $27 \%$. Finally, it is concluded that the regression equation given in this paper is a good alternative to compute linepack pressure other than using complex numerical modeling.

\subsection{Strengths and limitations of the proposed model}

The proposed method has simplified the computation of peak positive pressure surge caused by a quick acting downstream valve in a long distance pipeline. This method is based on hand calculator and sufficiently accurate. The method can be used by design engineers during the preliminary study of possible water-hammer pressure. This method is not an ultimate solution, and aids traditional numerical softwares. This method cannot be used for analyzing positive pressure surge with surge control devices in the system. Additionally, this method is not applicable for slow valve closures.

Table 4. Experimentally observed and estimated linepack pressures Adamkowski and Lewandowski [19].

\begin{tabular}{|c|c|c|c|c|}
\hline \multirow[b]{2}{*}{ S1. No. } & \multirow[b]{2}{*}{ Flow parameters } & \multirow[b]{2}{*}{$P_{L P}$ measured $(\mathrm{m})$} & \multicolumn{2}{|c|}{$P_{L P}$ estimated using Eq. (13) } \\
\hline & & & $P_{L P}(\mathrm{~m})$ & $\%$ error \\
\hline 1 & $\begin{array}{c}R_{\mathrm{e}}=5730 \\
V_{o}=0.34 \mathrm{~m} / \mathrm{s} \\
h_{L}=3.02 \mathrm{~m}\end{array}$ & 0.52 & 0.53 & 0.53 \\
\hline 2 & $\begin{array}{c}R_{\mathrm{e}}=10600 \\
V_{o}=0.63 \mathrm{~m} / \mathrm{s} \\
h_{L}=10.2 \mathrm{~m}\end{array}$ & 1.78 & 1.79 & 1.79 \\
\hline 3 & $\begin{array}{c}R_{\mathrm{e}}=15800 \\
V_{o}=0.94 \mathrm{~m} / \mathrm{s} \\
h_{L}=22.4 \mathrm{~m}\end{array}$ & 3.75 & 3.95 & 3.95 \\
\hline
\end{tabular}


Table 5. Measured and estimated linepack pressures Ellis [20].

\begin{tabular}{|c|c|c|c|c|c|}
\hline \multirow[b]{2}{*}{ S1. No. } & \multirow[b]{2}{*}{ Pipe section } & \multirow[b]{2}{*}{ Flow parameters } & \multirow[b]{2}{*}{$P_{L P}$ measured $(\mathrm{m})$} & \multicolumn{2}{|c|}{$P_{L P}$ estimated using Eq. (13) } \\
\hline & & & & $P_{L P}(\mathrm{~m})$ & $\%$ error \\
\hline 1 & At valve & $\begin{array}{c}R_{\mathrm{e}}=353632 \\
V_{o}=0.79 \mathrm{~m} / \mathrm{s} \\
h_{L}=17.75 \mathrm{~m} ;\end{array}$ & 16.98 & 12.27 & 27.73 \\
\hline 2 & At $8000 \mathrm{~m}$ downstream of the reservoir & $\begin{array}{c}R_{\mathrm{e}}=353632 \\
V_{o}=0.79 \mathrm{~m} / \mathrm{s} \\
h_{L}=7.25 \mathrm{~m}\end{array}$ & 5.80 & 6.63 & 14.22 \\
\hline
\end{tabular}

Table 6. Measured and estimated linepack pressures Kucienska et al [21].

\begin{tabular}{lcccc}
\hline & & & & \multicolumn{2}{c}{$P_{L P}$ estimated using Eq. (13) } \\
\cline { 3 - 5 } S1. No. & Pipe section & Flow parameters & $P_{L P}$ measured (m) & $P_{L P}(\mathrm{~m})$ \\
\hline 1 & At valve & $h_{L}=3.93 \mathrm{bar}$ & 4.08 & 4.44 \\
2 & At mid-section, $\mathrm{x}=25 \mathrm{~m}$ & $h_{L}=1.98 \mathrm{bar}$ & 3.51 & 3.57 \\
\hline
\end{tabular}

\section{Conclusions}

This paper deals with a forgotten and overlooked research problem, namely linepacking of incompressible flows in pipelines. It was believed that linepack pressure is produced entirely by friction. To investigate this assertion, effects of various parameters such as relative roughness, inlet pressure, Reynolds number and Mach number on the linepack pressure have been thoroughly investigated. As a result, Reynolds number, non-dimensional inlet pressure (Euler number) besides non-dimensional frictional headloss were found to be key parameters affecting the linepack pressure. In this study, pressure is non-dimensionalized by either inlet pressure or steady state dynamic pressure and the results are the same irrespective of the scaling parameter. The non-dimensional linepack pressure increases significantly as the relative roughness increased and the obtained proportionality constant is found to be 1.5 . It was established that linepack pressure decreases with increasing valve closure time. For a given constant roughness, linepack pressure increases with increasing Mach number, however, the rate of increase was very small. The increase in linepack pressure was considerable with increasing Reynolds number. Therefore, the dominant parameter which affects the linepack pressure was found to be the Reynolds number as compared to the Mach number and the relative roughness. In addition, linepack pressure was linearly proportional to frictional head loss $\left(h_{L} / D\right)$ and inversely proportional to inlet pressure $\left(P_{o} /\left(\gamma L_{o}\right)\right)$.

In the past, it was understood that the linepack pressure was equal to the pressure loss caused by the friction. However, in this research, it was found that for, $P_{f L} / P_{o}<0.1$ and $P_{f L} / \frac{1}{2} \rho V_{o}^{2}<0.01$ the linepack pressure was only $1 / 5^{\text {th }}$ of the frictional pressure loss, which demonstrates that not all the frictional headloss is contributing to the linepack. Finally, it is discovered that the ratio between linepack pressure and frictional headloss is not a constant, but a function of the ratio between frictional headloss and the inlet pressure. These are two important findings of the study. Consequently, a linear equation is proposed each for $P_{f L} / P_{o}>0.1$ and $P_{f L} / P_{o}<0.1$ to estimate the linepack pressure along the pipeline caused by instantaneous valve closure operations at the downstream end. The regression equation was also validated using the pressure histories caused by sudden valve closure available in the literature. The percentage error in calculating the linepack pressure with the proposed equation was found to be as low as $0.53 \%$ and as high as 27 $\%$. The proposed linear equation was simple, easy to use, and accurate, which needs only inlet pressure and steady state head loss. Finally, the proposed equation proved to be a good alternative to compute linepack pressure in a long water pipeline, which can be used by a field engineer without using the complex numerical modeling. Although, the linear regression equation to compute linepack pressure was developed for a simple series pipe system with pressure boundary condition at the inlet and sudden valve closure boundary condition at the outlet, the equation may also be applicable to branch pipelines in a complex water distribution network or in a fire water network as well.

\section{List of symbols}

$P_{L P} \quad$ linepack pressure (bar)

$\rho \quad$ mass density of water $\left(\mathrm{kg} / \mathrm{m}^{3}\right)$

$\gamma \quad$ self weight of water (Newton)

$a$ sound wave velocity $(\mathrm{m} / \mathrm{s})$

$V_{o} \quad$ steady-state velocity $(\mathrm{m} / \mathrm{s})$

$v \quad$ kinematic viscosity $\left(\mathrm{m}^{2} / \mathrm{s}\right)$

$D \quad$ diameter of pipe (m) 
$t \quad$ time coordinate $(\mathrm{s})$

$\lambda \quad$ friction factor $(-)$

$L \quad$ distance of a node from the beginning of the pipe (m)

$g \quad$ acceleration due to gravity $\left(\mathrm{m} / \mathrm{s}^{2}\right)$

$\Delta P_{j} \quad$ the instantaneous pressure rise given by Joukowsky equation (bar)

$\Delta V \quad$ the instantaneous change in velocity during the sudden valve closure $(\mathrm{m} / \mathrm{s})$

$h_{j} \quad$ instantaneous rise in pressure head (m)

$T_{r} \quad$ reflection time (s)

$x \quad$ distance co-ordinate $(\mathrm{m})$

$H \quad$ dynamic pressure head (m)

$Q \quad$ dynamic flow rate $\left(\mathrm{m}^{3} / \mathrm{s}\right)$

$A$ pipe internal cross sectional area $\left(\mathrm{m}^{2}\right)$

$\varepsilon \quad$ roughness height $(\mathrm{m})$

$Q_{o} \quad$ steady-state initial flow rate $\left(\mathrm{m}^{3} / \mathrm{s}\right)$

$C_{v} \quad$ valve flow coefficient $\left(\mathrm{m}^{3} / \mathrm{s} / \sqrt{b a r}\right)$

$\left(C_{v}\right)_{o} \quad$ valve flow coefficient during fully open condition $\left(\mathrm{m}^{3} / \mathrm{s} / \sqrt{\text { bar }}\right)$

$\Delta P_{o} \quad$ pressure loss across the valve during valve fully open condition (bar)

$Q_{P} \quad$ dynamic flow rate across the valve $\left(\mathrm{m}^{3} / \mathrm{s}\right)$

$\left(C_{v}\right)_{P}$ dynamic valve flow coefficient during fully open condition $\left(\mathrm{m}^{3} / \mathrm{s} / \sqrt{\text { bar }}\right)$

$\Delta P_{P} \quad$ dynamic pressure loss across the valve during valve fully open condition (bar)

$s \quad$ dimension-less valve coefficient, which is the ratio of flow coefficient during dynamic conditions to flow coefficient during valve fully open condition $(-)$

$\varepsilon / D \quad$ relative roughness $(-)$

$P_{o} \quad$ constant inlet pressure (bar)

$h_{L} \quad$ steady-state head loss (m)

$\frac{v_{o}}{a} \quad$ Mach number (-)

$\stackrel{a}{H}_{S} \quad$ steady-state pressure head at the valve (m)

$P_{f L} \quad$ frictional pressure loss during steady-state (bar) $=\rho g h_{L}$

$a_{1} \quad$ slope of linear regression equation-1 (-)

$b_{1} \quad$ intercept of linear regression equation-1 (-)

$a_{2} \quad$ slope of linear regression equation-2 (-)

$b_{2} \quad$ intercept of linear regression equation-2 (-)

$R_{e} \quad$ Reynolds number (-)

$L_{o} \quad$ pipe length from beginning to the valve (m)

\section{References}

[1] Joukowski N E 1898/1900 Mem. Imperial Academy Soc. of St. Petersburg, vol. 9. no. 5, (in Russian. translated by O. Simin, Proc. Amer. Water Works Assoc., vol. 24, 1904. pp. 341-424.) Kerensky, G., 1965-1966, Discussion
[2] Kaplan M, Streeter V L and Wylie E B 1967 Computation of oil pipeline transients. J. Pipeline Div. Am. Soc. Civil Eng. 93(4): 59-72

[3] Kries J von 1892 Studien zur Pulslehre (Studies of the pulse), (Akademische Verlagsbuchhandlung von) JCB Mohr (Paul Siebeck), Germany: Freiburg im Breisgau und Tübingen (in German)

[4] Tijsseling A and Anderson A 2007 Johannes von kries and the history of water-hammer. J. Hydraul. Eng. 133: 1-8

[5] Jung B S, Boulos P F and Wood D J 2009 Effect of pressuresensitive demand on surge analysis. J. Am. Water Works Assoc. 101: 100-111

[6] Jung B S, Karney B W, Boulos P F and Wood D J 2007 The need for comprehensive transient analysis of distribution systems. J. AWWA, 99:112

[7] Watters G Z 1984 Analysis and control of unsteady flow in pipelines, London: Butterworths

[8] Fox J S 1989 Transient flow in pipes, open channels and sewers. Chichester: Ellis Horwood Limited

[9] Thorley A R D 2004 Fluid transients in pipeline systems, 2nd edition, Jon Wiley and Sons Ltd

[10] Wylie E B and Streeter V L 1993 Fluid transients in systems, Englewood Cliffs: Prentice-Hall

[11] Hanmaiahgari P R, Elkholy M and Riahi-Nezhad 2017 Identification of partial blockages in pipelines using genetic algorithms. Sādhanā. 42: 1543-1556. https://doi.org/10. 1007/s12046-017-0707-8.

[12] Balamurugan M and Bhallamudi S M 2016 Flood routing in an ephemeral channel with compound cross-section. Sädhanā 41: 771-785. https://doi.org/10.1007/s12046016-0511-x

[13] Chaudhry M H 2013 Applied hydraulic transients, 3rd ed, New York: Springer

[14] Martin C S 2000 Hydraulic transient design in pipeline systems. In: Mays L W (ed) Water Distribution Systems Handbook. New York: McGraw-Hill

[15] White F W 2006 Fluid mechanics, New York: McGraw-Hill

[16] Gudmundsson J, Durgut I, Rønnevig J, Korsan,K and Celius H 2002 Pressure pulse analysis of flow in tubing and casing of gas lift wells. Spring ASME/API Gas Lift Workshop, Houston

[17] Liou C P 1991 Maximum pressure head due to linear valve closure J. Fluids Eng. 113: 643-647. https://doi.org/10.1115/ 1.2926528

[18] Ghidaoui M S, Zhao M and McInnis D A 2005 A review of water-hammer theory and practice, Appl. Mech. Rev. 58: 49-76. https://doi.org/10.1115/1.1828050

[19] Adamkowski A and Lewandowski M 2006 Experimental examination of unsteady friction models for transient pipe flow simulation. J. Fluids Eng., ASME. 128: 1351-1363

[20] Ellis J 2008 Pressure transients in water engineering, a guide to analysis and interpretation of behaviour. London: Thomas Telford Limited

[21] Kucienska B, Seynhaeve, J and Giot M 2008 Friction relaxation model for fast transient flows application to waterhammer in two-phase flow-The WAHA code. Int. J. Multiph. Flow. 34: 188-205

[22] Kucienska B 2004 Friction relaxation model for fast transient flow. Universite' catholique de Louvain (UCL). Doctoral thesis 